\title{
Comparative Effects of Biogeography, Ecology and Radiation on Morphology of Some Cranial Varia- bles in Raccoon Dogs Species (Nyctereutes procy- onoides)
}

\section{Samuel O.M ${ }^{1,2}$, Olopade $\mathrm{J}^{\mathrm{O}^{2 \star}}$ and Onwuka S.K ${ }^{2}$ \\ ${ }^{1}$ Department of Veterinary Anatomy University of Ibadan, Nigeria, \\ ${ }^{2}$ Department of Veterinary Anatomy University of Agriculture Makurdi, Nigeria}

Received June, accepted for publication September 2015

\section{Abstract}

The present adimension in tropical N. procyonoides. Comparable architecture and construction was found in mandibular height at $\mathrm{M}_{1}$ as well as Koronium to angular process length, cheek tooth row length diverged widely across geographic locations being highest and lowest in Polish and tropical species respectively. Divergence also occurred in rostral and caudal viscerocranial lengths, a similarity in the latter parameter between Ussuriensis and subject of this survey was observed. Maximum palatal length was lowest in Ussuriensis and highest in tropical species. The study concludes that origin, possible genetic distance, period of radiation and human activities impacted on changing skull parameters. Mainland species from Japan appears smaller sized compared to island versions. Newer geographic areas

J. Vet. Anat. of introduction of this species demonstrated an up-regulation in some cranial parameters.

Keywords: Raccoons (Nyctereutes procyonoides), paleogeographic locations, skull morphology, skull bones plasticity

\section{Introduction}

Raccoons form the fossil carnivores of the Pliocene (Bjork, 1973). Unlike the procyonids such as the crabeating raccoon ( $P$. cancrivorus) the ancestors of the common raccoon left the tropical and subtropical areas and migrated farther north about 2.5 million years ago, confirmed by the discovery of fossils in the Great Plains with Pliocene period dates (Hohmann et al.2001) and believed to have originated from Eastern Asia (Kauhala et al., 1998). The adult weighs between $1.8-4.5 \mathrm{~kg}$ (Rathburn, 2003). The nocturnal carnivore-omnivore's diet consists 
of $40 \%$ invertebrates, $33 \%$ plant materials and $27 \%$ vertebrates (Zevellof, 2002), this proportion alters with season and availability (Feldhamer et al. 2003) and is one of the most variably sized animals (Mc Clintock, 1981) with males being about $15-20 \%$ heavier than females.

Sympatric with the common raccoon (De La rossa and Nocke, 2000; Eisenberg and Redford, 1999; Happolds, 1987), confirmed the presence of $P$. lotor in the southwestern region of Nigeria with a similar eco-environ-ment to the $P$. cancrivorus especially along riverine and mangrove rainforest areas (Happolds, 1987). First recordings in Germany was in 1927 (Homann et al. 2001), introduced into Russia in 1936 from Berlin (Kowalczyk, 2001; Sutor, 2008)and later into the middle part of the continent, their European ranges increased to Poland (Nwicki et al. 2011), Belorussia (1936) and Yugoslavia, Latvia (1948) and Estonia; all, of different climatic and paleo-geographic conditions (Griciuviene et al. 2013;Prusaite et al, 1998). Tropical ecology, dictated by precipitation, forest structure fragmentation, intertropical discontinuities and temperature (Ita, 1994) influences both flora and fauna types availability.

Comparative literatures on cranial morphologic elasticity in raccoon dogs (Nyctereutes procyonoides) are relatively scarce; when available it has been attributed to introduction, selective release and founder events as a result of limited genetic diversity. Earlier studies established several cranio-structural differentials between Japanese raccoon dogs and those from the mainland populations; also those results from these may not be valid for European species (Mulder, 2011). This observations has been partly attributed to migrations, environmental factors and genetic inputs (Pergams and Lawler, 2009), overtime, variable ontogeny characters evolve thereby making biogeography anthropologic investigations among different species populations a necessity for surveillance and in solving taxonomic ambiguities (Hidaka et al. 1997). The present investigation aims to compare certain cranial indices of tropical raccoons (Nigeria) using morphometric data to establish the rapid morphological changes and plasticity of these parameters in the species with location and radiation. Isolated cranial studies on raccoon dogs from different countries are numerous including Japan (Hidaka et al. 1997), Finland (Kauhala et al. 1998), Russia (Kowalczyk, 2011) Germany (Mulder, 2011), and South Korea (Kim et al. 2012). No available record indicated when the species was introduced to the tropics 
despite several sightings (Happolds, 1987).

\section{Materials and Methods}

\section{Ethical Statement}

Animal experiments done in this study were based on the regulations of the ethical committee of Faculty of Veterinary Medicine of the University of Ibadan.

\section{Data Assessment Information}

\section{Animals}

A total of 40 (20 males \& 20 females) adult raccoon dog heads (Nyctereutes procyonoides Spp.) obtained from southwestern region of Nigeria were used. Cervical decapitation was carried out followed by weighing of heads after body weight recordings for each animal. Frozen heads were thawed out and processed for skull maceration as described by Onar (2001). Similar linear models were compared with the species from Japan, Finland, Russia and South-Korea.

\section{Skull and Mandible Images}

The macerated skulls were digitally photographed using EOI 1200D CANON camera equipped with 18$55 \mathrm{~mm}$ telephoto kit and pictures taken with 5.6 focal, 200 speed, DIN- $40 \mathrm{~cm}$, and sensitivity of $1 / 500$ for all views of skulls assessed. Background was screened using
Microsoft windows software version 6.1 (Build 7601 service packs). Cranial variables in picture preparation and measurements evaluated from skull pictures were done with MOTIC IMAGES 2.0 (2007). Dental eruptions and wears were used in selecting specimen for this investigation and Photographs were taken without mandible and place on dorsal, left lateral and ventral views and scaled for size with ruler points. Graph Pad Prism 4.03 (Graph-Pad software, 2008) was used in analyses utilizing a two way ANOVA.

\section{Landmark of indices evaluated}

SK-i- Skull index= Maximum zygomatic width $x$ 100/Skull length (Inion-Posthion)

F-i- Facial index= Maximum zygomatic with $x$ 100/Viscero-cranial length (Nasion to posthion)

NC-i - Cranial index -Maximum neuro-cranial width $x 100 /$ cranial length (Nasion to Inion)

MNC-W - Maximum neuro-cranial width -Measured from the widest lateral limit of the brain case(Fig 2b)

$A V C L-D i s t a n c e$ from the most midline point of the incisive bone to the most dorsal point of the nasal bone (Posthion- Nasion)(Fig 2b)

$P V C L$-Distance from the most dorsal point of the nasal bone to the 
most caudal point of the occipital protuberance(Nasion-Inion)(Fig 2b)

SK-L- Skull length -Measured from the posthion to the inion; Distance from the rostral midpoint in the incisive bone to the most caudo-midline projection of the skull (Fig 2b).

$\boldsymbol{S} K-\boldsymbol{h}$ - Skull height- Distance from the highest point of the nuchal crest to the base of the skull without the mandible (Fig 1)

MFW -Maximum frontal width Distance between the lateral frontal eminences of the frontal bones(Fig $2 b)$

MZ-W - Maximum zygomatic arches width - Distance from the most lateral points of the zygomatic bones (Fig 1)

NL- Nasal bone length -Measured from the most dorsal point of the nasal bone to the rostral medial limit (Fig 2b)

OC-W - Maximum width of occipital bone across Opisthion (Fig 1)

mPL- Maximum palatal length Distance measured from the midline of the mid rostral end of the choana to the tip of premaxilla (Fig 2a)

MDH - Height of vertical Ramus Measured from the base of the mandible vertically to the tip of the coronium (Fig 3 a)
MHM $\mathbf{M}_{1}$-Height of mandible, below $\mathrm{M}_{1}$ ( $1^{\text {st }}$ molar) (Fig 3 a)

K-c-Maximum distance from koronium to condyle (Fig 3 a)

C-Ap- Distance between condyle and angular process (Fig 3 a)

LCT- Length of cheek tooth row taken from the canine tooth to the last molar tooth (Fig 3 a)

$S-A p$ - Length from ventral mandibular spine to angular process tip ventrally.

The parameters obtained were also compared with similar data in raccoons from different regions of the world as recorded in the literature.

Mandibular spine assessments in tropical species had a mean distance of $24.21 \mathrm{~mm}$ from corresponding angular process on the same side and were not priory evaluated in the species from other locations.

\section{Results}

All evaluated indices varied significantly at $(P<0.0001)$ excepting/MZ$W /$ values with sequential Bonferroni corrections.

Pattern of representation $/ \mathrm{MH} /$ in this survey and demonstrated dissimilarities assessed for the current subject showed a relatively high mandibular height significantly $(P<0.0001)$ higher Bonferroni post- 
test showed / MH-M 1 and / Kc-C-Ap / were significantly $(P<0.0001)$ different in dimensions.

\section{Discussion and conclu- sions}

General trends and study hypothesis Observations revealed that tropical species of the wildlife in the enquiryare significantly smaller sized in some cranial variables assessed compared to similar species from Russia, Japan and Finland. Skull size has been correlated with body size (Khulenbeck, 1973; Dyce et al. 2002). Raccoon dogs of fossil times have been found comparatively larger than contemporary species (McClintock, 1981). Definite craniometric plasticity for intraspecific distinctions in various regions not only point to answers to anthropologic queries but suggests an influence of civilization, shrinking ecology, reducing fauna and adaptation for survival in less commodious environment.

Our results confirms subtle phenotypic differences in the skulls of the five species understudied and permits us to reject hypothesis that paleo-geographic range might not have profound effects on skull profiles (Yazdi and Adriens, 2013) as seen in figs $3 b$ and 5 . Differing food habits and occlusion patterns in morpho-physiology of mastication and deglutition were responsible for the changes observed in the parameters investigated ( $\mathrm{He}$ and Kiliaridis, 2003; Ellis et al. 2009; Foth et al. 2015).

\section{Ecology, diet and morphology}

There was double convergence of facial indices in the tropical and polish species (higher) and Finnish, Japanese and Korean raccoons (lower) on the other hand Overlaps in many parameters notwithstanding, (/OC-W/) was found significantly larger in the presently investigated species in relation to a longer profile length which might indicate a broader skull width and more carnivore cranial typology compared to the Finnish, further confirmed by their higher mean $\left(/ \mathrm{MH}-\mathrm{M}_{1}\right)$ values, and suggestive of better accessibility to a richer ecology in terms of high fracture resistance diet and range (Pergams and Lawler, 2009), this mandible morpho-type at $M_{1}$ demonstrates more robust configuration at this crushing point in prey summarization compared to a less /more slender type which better conform to a more herbaceous diet composition (Ellis, et al. 2009; Foth et al. 2015).Whereas, a longer cheek tooth row (/LCT/) in Russian type may substantiate previous suggestion but the mean values falls inversely with population in the locations evaluated (Latrov, 1971; Griciuviene et al. 2013) perhaps urbanization increase and reduced 
spatial range impacted on available diet over time with a resultant morpho-physiologic reconstructions of masticatory apparatuses (Dyce et al. 2002; Foth et al. 2015).

\section{Functional morphology}

The findings of this study corroborates bite force study in raccoons from these locations which according to Samuel et al. (2015) increases with body weight, profile length, facial ratio, skull width and index (Christianson and Wroe, 2007; Foth et al. 2015) It is worth observing that ancestral original (Asian) species and morphologic alterations reported subject to distance, and radiation of the species. N. p. Koreensis and N. p. ussuriensis seems to share many morphological similarities and differ considerably from $N$. p. viverrinus which has been suggested to be a new evolving species (Kauhala et al. 1998; Bartussek and Boer, 2001).

Nyctereutes procyonoides from tropical environments revealed certain conformational similarities with those from Finland with reference to $S K-h$, SK-I (fig. 4a), PVC-L, /Kc-C$A p /$ and $/ M H-M_{1}$. Nowicki et al. 2011; Hidaka et al. 1997; Kim et al. 2012), WhileF-i, /AVCL//MH-M 1 , /MZ-W/ and /MP-L/ (Fig 5) were comparable with $\mathrm{N}$. procyonoides from Poland. The observation in these parameter attri-butes is indic- ative of species affinity or related phylogeny (Figuerido et al. 2009). N. p. koreensis (South Korea) shared character similarities as $S K$ $h, S K-I, / M H /, M H-M_{1}$ and /Kc-C-Ap/ with others (Fig 6a \& b). Significant differences seem to occur more in nasal, maximum palatal bone lengths, neuro-cranial index which substrates for the differentials in facial index (Kunzel and Opel, 2002). Nasal and palatal bone lengths are species discriminant variables, which varied noticeably with paleogeography (Mac Clintock, 1981), and are utilities in hunting and assessing food from crevices or for phonation, which may be dimorphic between genders (Mulder, 2011). Further investigations may be necessary to clarify extent and limits of morphologic integration, canalization and developmental instability (Gibson and Wagner, 2000; Hallgrimson et al. 2002) in species locations.

Facial index analysis divided the continental species into two categories consisting of a higher index group (155-156) including Polish and tropical types and a lower (119122); Finnish, Japanese and SouthKorean group. A highest /SK-L/ value being reported in tropical raccoon dogs with contributions from nasal and palatal lengths to the facial profile shown is postulated to be as a result of ontogenic shifts and of 
relevance in anthropologic studies (Koepfli et al. 2007; Maldonado and Wayne, 2007, Foth et al. 2015). This has been attributed to a later explosive introduction to the ecoenvironent fauna type (Prusaite et al. 1988; Mulder, 2011); this location-dependent variable has been reported in other invasive wildlife species (Hohmann et al. 2001; Mac Clintock, 1981; Figuerido et al. 2009; Pergams and Lawler, 2009).

Invasion, introduction and re- introduction into new areas have been largely reported to contribute to size elasticity (Griciuviene et al. 2013; Prusaite et al. 1988). While founder and local effects, climatic phenomenon and other stress factors (Zevellof, 2002) are possible causes of high non-uniformities in available data, relative onset of civilization and development activities has been documented to impact on ecoenvironment (Pergams and Lacy, 2007). Animals caught from Amursk (Griciuviene et al. 2013) being earlier introduced were larger than those from Lithuania with a higher condylo-basal length compared to those taken from Nigeria, despite this, several skull component dimensions have been observed relatively shortened including caudal viscero-cranial length $(P \vee C-L)$ and rostral viscero-cranial length $(A V C-L)$ resulting in the group highest neuro-cranial and a second highest facial index (Fig 5). This seeming ventral prolongation and dorsal recession of the skull bones in this tropical variant demonstrated by its relatively reduced nasal bone length/NL/ but most bowed $/ M Z-W /$ (Fig 6a) among the types contributed significantly to a smaller $/ L C T /$, a level of intraspecific variations in this as in other assessments make conclusive diagnostic criteria derivations difficult (Struthsaker, 1981) but are defining elements of fauna type, quality and climatological conditions especially so in high temperature ecologies (Nowicki et al. 2011). The convergence observed in $\left(\mathrm{MH}-\mathrm{M}_{1 /}\right)$ across location skull typologies (Fig 6b) confirms a similar region of predicted bite force (Ellis et al., 2009). However, a comparison with previous functional studies reveals that functional adaptations during ontogeny seem to be primarily restricted to the ventro-caudal region whereas rostro-dorsal shape changes are more related to dietary shifts.as confirmed by findings of on-going study on the subject (Samuel et al., 2015), diet dependence and characteristic of a common phylogeny (Koepfli et al. 2007). However, cross comparison of ventro-caudal mandibular spine was not possible as it was peculiar to males in tropical species (Fig 3b). 
A compensation of structural construction in skulls of this species from a wide geographical range would allow results of our analysis to provide a solid base for the extraction of usable and reliable diagnostic traits that can be implemented for identification and a tool in solving taxonomic challenges in raccoons. Cultivar classifications of shapes and automated quality assessment methods as previously developed (Costa et al. 2011), these models though discriminates between morpho-types are based on a priori assumptions of species and population classes, it may be confirmatory to apply an open method approach where specimen could be put in non- predefined class especially in exceptional cases where the former could not fit (Yazdi and Adriaens, 2013; Struthsaker, 1981).

Assessment of these parameters postulates that the presently evaluated species may have been around for longer than earlier thought, having enjoyed adaptive radiation from Europe or perhaps are evolving newer species. A necessity for proper classification based on geographic re-evaluation is proposed. The study brings to fore a rapid morphological cranial change in raccoon's skulls as enlargements occur in their eco-location ranges and attempts to contribute in clarifications of skull morpho-types and biodiversity based on fauna types, relative time of recorded presence, encroachment of human activities and temperature deviations in unpredictable climate changes in five different ecologies. Further studies on comparative seasonal variations in precipitations and pressure as it affects fauna quality are necessary.

Conflict of Interests statementThe authors declare no conflict of interests

\section{References}

Bartussek, I.,B. Böer (2001): Der Waschbär. Reutlingen, Germany: Oertel+Spörer.ISBN978-3-88627301-0 Pp. 82

Bjork, P.R. (1973): Transactions of the Kansas Academy of Science (1903-) Vol.76, No.1(Spring,) ,pp. 24-38, Published by: Kansas Academy of Science Article Stable URL: http://www.jstor.org/stable/3627248

Christiansen, P., Wroe, S. (2007): Bite forces and evolutionary adaptations to feeding ecologies in carnivores (Mammalia, Carnivora) J Zool. Lond 266, 133-151

De La Rosa and Nocke, (2000): Guide to the carnivores of Central America, Austin: University of Texas Press 43 
Costa, C., F. Antonucci, F. Pallotino, J. Aguzzi, D. W. Sun, P. Menesatti (2011): Shape analysis of agricultural products: a review $f$ recent research advances and potential application to computer vision. Food Bioprocess Technol 4:673-692

Dyce, KM, Wensing CJG, Sack WO (2002): Textbook of Veterinary anatomy, $3^{\text {rd }}$ edition, Saunders publication

Eisenberg, J., K. Redford, (1999): Mammals of the neotropics, London: University of Chicago press

Ellis,J.L, J.Thomason, E.Kebreab, K.Zubair and J. France (2009): Cranial dimensions and forces of biting in the domestic dog J. Anat. 214, $p$ p 362-373

Feldhamer, G., B. Thompson, J. Chapman (2003): Wild mammals of North America. Baltimore and London: The John Hopkins University press 117.

Figueirido,B., P. Palmqvist, J. A. $\mathrm{Pe}^{\prime}$ rez-Claros (2009): Ecomorpho-logical correlates of craniodental variation in bears and paleobiological implications for extinct taxa: an approach based on geometric morphometrics Journal of Zoology 277: 70-80

J. Vet. Anat.
Foth, C. Bona, P., Desojo, J. B (2015): Intraspecific variation in the skull morphology of the black caiman Melanosuchusniger (Alligatoridae, Caimaninae) Acta Zoologica (Stockholm) 96: 1-13

Gibson G, Wagner G. (2000): Canalization in evolutionary genetics: a stabilizing theory? Bioessays 22, 372-380.

Graphpad software (2008): San Diego California USA, www. Graphpad. com

Griciuviene, L., A. Paulauskas, J. Radzijevieskaja, V. Gedminas (2013): Variability of Skull morphometic characters in Nyctereutes procyonoides. Biologija, Vol. 59, No.2 151-165

Happold, D.C.D. (1987): The Mammals of Nigeria, Clarendon Press, Oxford, 122-144

He, T., Kiliaridis, S. (2003): Effects of masticatory muscle function on craniofacial morphology in growing ferrets (Mustela putorius furo) Euro J Oral sci. 111, 510-517

Hidaka Sachinobu, Matsumoto Mitsuharu, HijiHirumi, Ohsako Seii-chiiroh and Nishinakagawa Hayao, (1997): Morphology and morphometry of skulls of raccoon dogs Nyctereutes Procyonoides J. vet. Med. Sci. 60 (2) 161-167 
Hohmann, U., Bartussek, I. Böer, B. (2001): (in German). Der Waschbär. Reutlingen, Germany: Oertel+Spörer. ISBN 978-3-88627301-0. Pp. 82

Ita, E.O. (1994): Aquatic Plants and Wetland Wildlife Resources of Nigeria. CIFA Occasional

Khulenbeck, E, (1973):Overall Brain Size, and Not Encephalization Quotient, Best Predicts Cognitive Ability across Non-Human Primates. Brain Behav. Evol 2007; 70:115124 (DOI: 10.1159/000102973)[1]

Kauhala, K, S. Viranta, M. Kishimoto, E. Helle and I. Obara, (1998): Skull and tooth morphology of Finnish and Japanese Raccoon dogs, Finnish zoological and botanical publishing Ann. Zool. Fennici. 35:1-16

Koepfli K. P., M. E. Gompper, E. Eizirik, C.C. Ho, L. Linden, J. E. Maldonado, R. K. Wayne (2007): Phylogeny of the Procyonidae (Mammalia: Carnivora): Molecules, morphology and the Great American Interchange". Molecular Phylogenetics and Evolution 43 (3): 10761095.doi:10.1016/j.ympev.2006.10. 003. PMID17174109

Kim, S., Suzuki, S., Oh, J., Koyabu, D., Oshida, T., Lee, H., Min, M., Kimura, J. (2012): Sexual Di- morphism And Craniodental morphology of raccoon dog (Nyctereutes procyonoides) from South Korea J. Vet. Med. Sci. 74(12): 1609-1616

Kowalczyk, R. (2011): NOBANISInvasive alien species fact sheetNyctereutes procyonoides Online database of the North European and Baltic network on invasive alien species 1-8

http://www.nobanis.org/files/factshe et/nyctereutes_procyonoides.pdf [consulted dd 1 September 2011]

Kunzel W.O B., M.Opel (2002): Morphometric investigationof breed specific features in feline skulls and consideration on their functional implications. Anat. Histol.embryol. 32: 218-223

Latrov, N.P. (1971) The results of the introduction of the raccoon dog (Nyctereutes procyonoides) in different provinces in the U.S.S.R. Trudy kafedry biologii MGZPI 29:101-1066 (In Russian)

Mac Clintock, D. (1981): A Natural History of Raccoons- Caldwell, New Jersey: The Blackburn Press. ISBN 978-1-930665-67-5

Maldonado, R, Wayne K. (2007): Phylogeny of the Procyonidae (Mammalia: Carnivora): Molecules, morphology and the Great American

Vol. 8, No. 2, (2015) 29 - 45 
Some Cranial variables in raccoon Dogs

Interchange". Molecular Phylogenetics and Evolution43 (3): 1076-1095.

Mulder, J.L. (2011): Voedsel en WarenAutoriteit- The raccoon dog in the Netherlands- A risk assessment Rapport Bureau Mulder-natuurlijk, De Bilt NL Commissioned by Team Invasieve Exoten Ministerie Van Economische Zaken, Landbouw en innovatie

Nowicki, W., W. Brudnicki, B. Skoczylas (2011): Studies of interdependence between characteristics in raccoon dogs (Procyonoidesnyctereutes Gray) EJPAU 14(2), \#17

Onar, V., Ozcan,S. and Pazvant, G. (2001) Skull typology of the adult male Kangal dog Anat Histol Embryol, 30: 41-48.

Pergams, R.W.O., J.J. Lawler (2009): Recent and widespread Rapid morphological Change in Rodents Plosone 4(7): e6452 doi: $10.1371 /$ journal.pone. 0006452

Pergams, O.R.W., Lacy, R.C., (2007): Rapid morphological and genetic change in Chicago-area Peromyscus Mol. Ecol. 17: 450-463

Prusaite, J., R. Mazeikyte, D. Pauza, N. Pauziene, R. Baleisis, R. Juskaitis, A. Mickus, A. Grusas, R. Skeiveris, P. Bluzma, O. Bielova, K. Baranauskas, A. Malcionis,
Samuel et al.

L. Balciauskas, Z. Janulaitis (1988): Fauna of Lithuania. Mokslas, $178-83$

Rathbun J. M (2003): The new skunks of the genus mephitis. Full text of proceedings of Boilogical society of Washington 27-30 www.google. Com, the skunk

Rohlf, F.J. (2010): tpsDigversion 2.16 New York; Department of Ecology and Evolution, State University of new York at Stony Brook, N.Y

Samuel, O.M, Cassanova, P.M., Olopade, J.O.(2015): On-going study on comparative cranial bite force components in raccoon dogs

Struthsaker, T.T. (1981): Vocalization, phylogeny and paleogeography of red colobus monkeys (Colobusbadius) Afr. J. Ecol 19:265-283

Sutor, A. (2008): Dispersal of the alien raccoon nyctereutesprocyonoides in southern Bradenburg, Germany. Eur. J. Wildl. Res. 54: 321-6

Yazdi, F.T., D. Adriaens (2013): Cranial variations in Merionestristami (Rodentia; Gerbilinae) and its morphological comparison with Merionespersicus, MerionesVinogradovi and Merioneslibycus: a geometric morphometric study J Zoolog Syst. Evol Res doi: 10.1111/jzl 12020 
Zeveloff, S.I. (2002):Raccoons: A Natural History. Washington, D.C.:
Smithsonian Books. ISBN 978-158834-033-7.

\section{Corresponding author:}

Prof J.O Olopade

Department of Veterinary Anatomy

University of Ibadan, Nigeria

E-mail: jkayodeolopade@yahoo.com

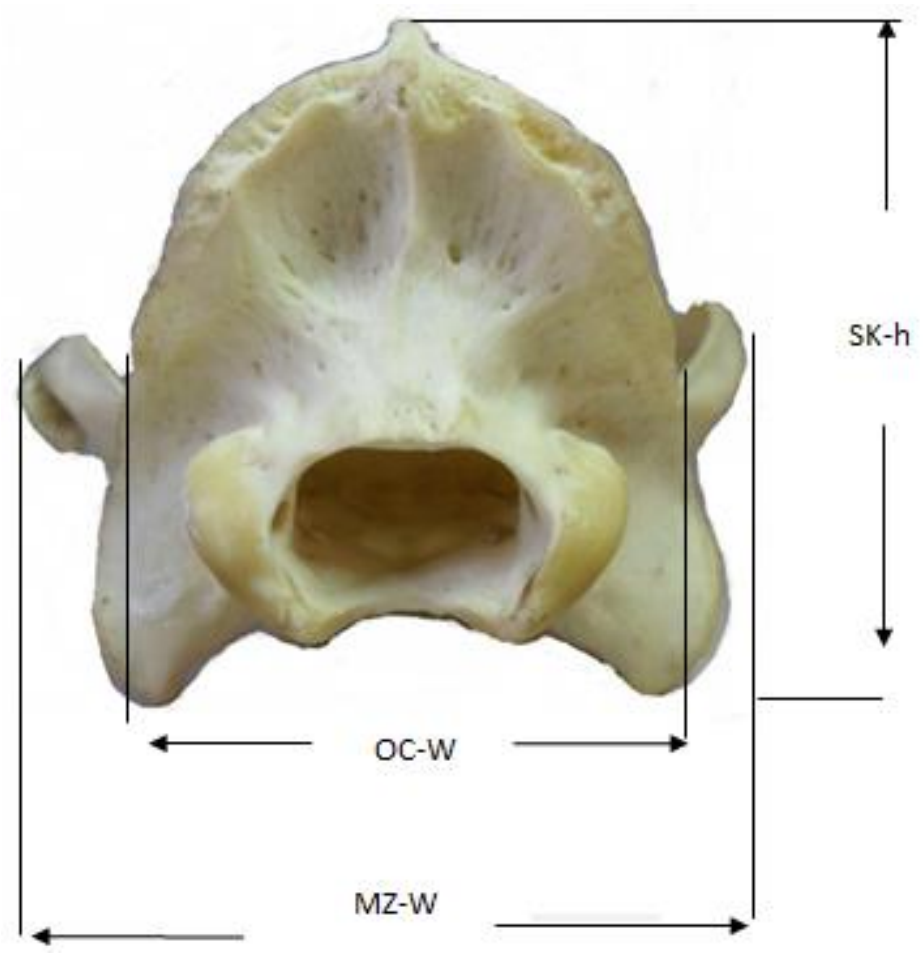

Fig (1): Caudal view of the skull of adult N. Procyonoides showing the following parameters- Occipital condyle width (OCW), Occipital width across opisthion(/OC-W/), maximum zygomatic width (/MZ-W/) and skull height (/Sk-h/). 


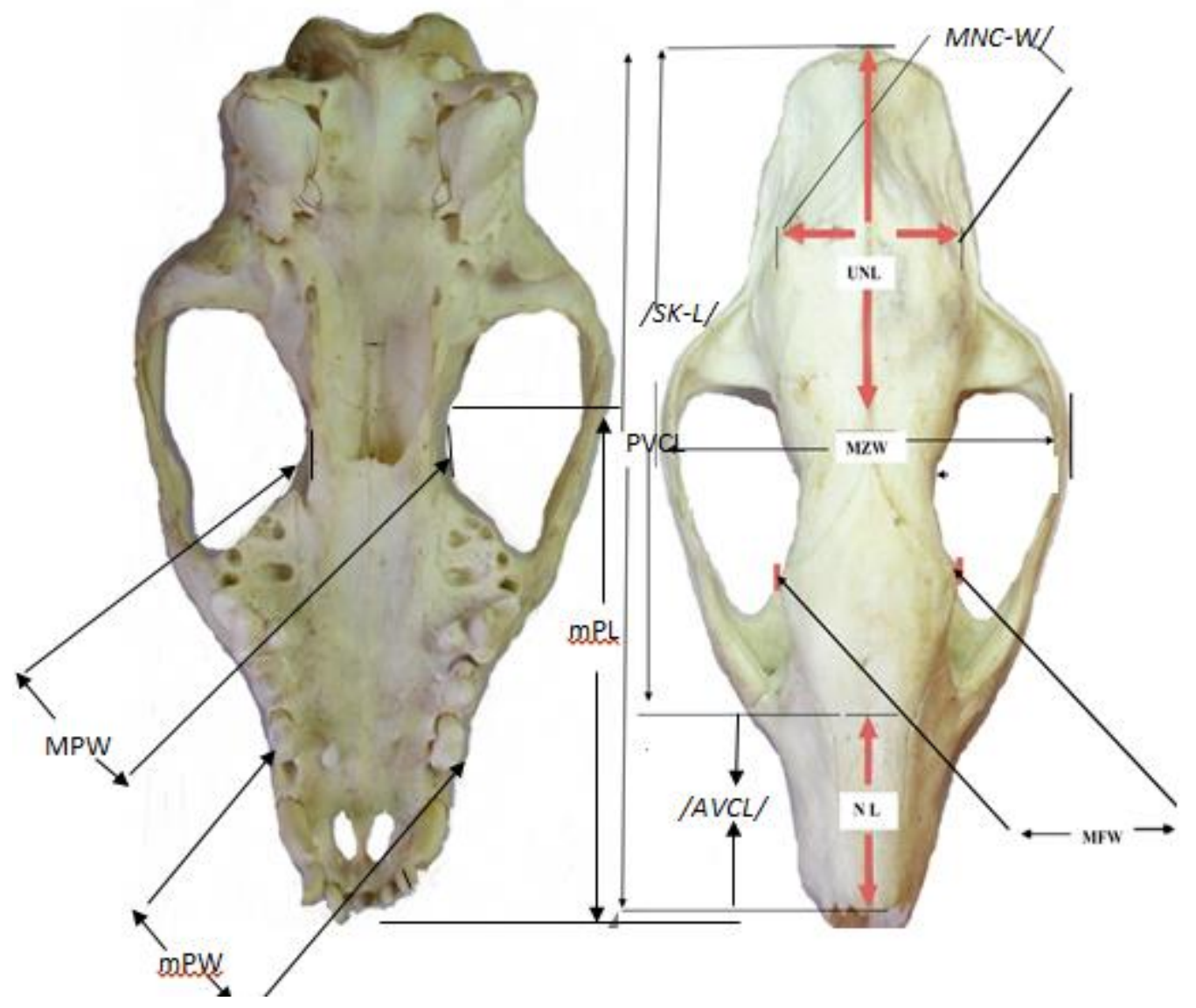

Fig (2):(a) Ventral view of adult female N.procyonoidesskullshowing minimum palatal width, maximumpalatal length (/MPL/) and Maximum palatal width (MPW)

(b) Dorsal view of the skull without mandible of adult female procyon showing the following parameters- Nasal bone length (NL), Maximum frontal width (MFW), Maximum zygomatic width (/MZW/),Zygomatic width (Zyg-W), Maximum neuro-cranial width (/MNCW/), rostro-viscero-cranial (/AVCL/) and caudo-viscero-cranial (/PVCL/) lengths. 

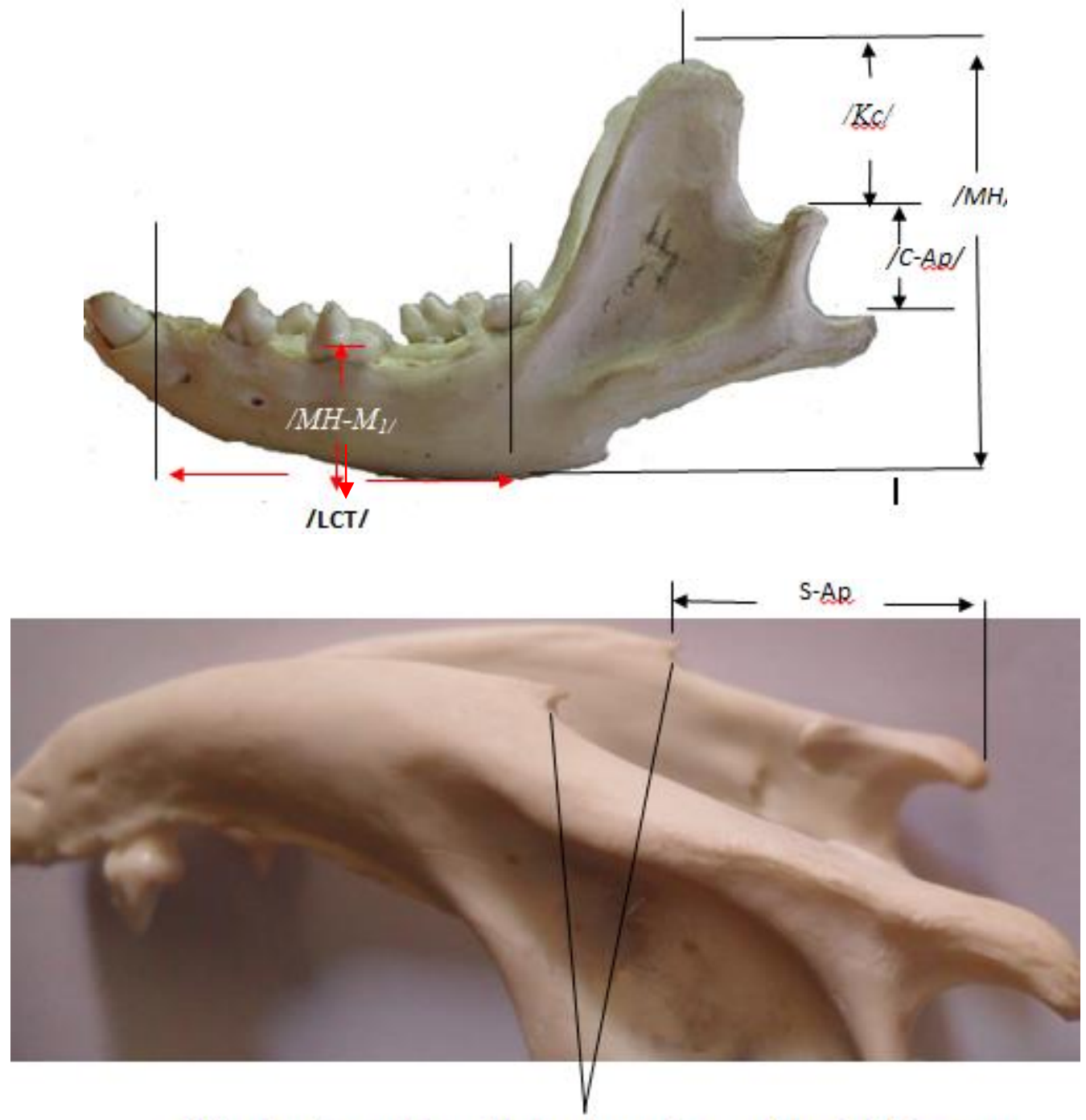

Bilateralyentro-caudal mandibular spine on the mandible of adult Prosvon

Fig (3 a ,b): Left lateral view of the left mandible of the adult female P. nyctereutes showing the following dimensions- Condyle to angular process (/C-Ap/), mandibular height at $\mathrm{M}_{1}\left(/ \mathrm{MH}-\mathrm{M}_{1}\right)$, Koronium to condyle process $(/ \mathrm{K}-\mathrm{c} /)$, length of cheek tooth row (/LCT/) and mandibular height (/MH/) (b)Ventro-caudal view of N. Procyonoides showing bilateral, ventral and caudally directed mandibular spine 
Some Cranial variables in raccoon Dogs

Samuel et al.

Table (1): Showing skull parameters for Finnish, Japanese, Russian South-Korean and Nigerian species of P.nyctereutes. ${ }^{a}$ (Kauhala et al., 1998), ${ }^{b}$ (Hidaka et al., 1998),

'(Nowicki et al., 2011; Griciuviene et al., 2013), ${ }^{d}$ (Kim et al., 2012)

\begin{tabular}{|c|c|c|c|c|c|}
\hline $\begin{array}{c}\text { Variables } \\
\text { (mm) }\end{array}$ & ${ }^{\mathrm{a}}$ Finnish & bJapanese & ${ }^{c}$ Russian & ${ }^{d}$ South Korea & Nigerian \\
\hline /SK-L/ & $124.1 \pm 3.8$ & $114 \pm 3.64$ & $117.5 \pm 0.31$ & $115.73 \pm 10 . .31$ & $149.2 \pm 0.83$ \\
\hline /SK-h/ & $46.50 \pm 1.55$ & $42.70 \pm 1.40$ & $59.0 \pm 5.32$ & $43.79 \pm 2.33$ & $46.6 \pm 3.61$ \\
\hline$S K-i$ & 52.38 & 90.35 & 66.30 & 57.92 & 52.48 \\
\hline$N C-i$ & 48.56 & 53.28 & 52.98 & 48.34 & 72.99 \\
\hline$F-i$ & 122.66 & 119.10 & 156.42 & 121.10 & 155.92 \\
\hline /MFW/ & $33.8 \pm 2.67$ & $34.1 \pm 2.21$ & $34.9 \pm 0.23$ & $33.37 \pm 2.67$ & $34.9 \pm 2.12$ \\
\hline /NL/ & $45.5 \pm 2.89$ & $42.6 \pm 2.64$ & $40.13 \pm 0.18$ & $44.62 \pm 9.37$ & $30.0 \pm 3.1$ \\
\hline /MZ-W/ & $70.90 \pm 2.47$ & $63.6 \pm 2.52$ & $77.9 \pm 0.30$ & $67.03 \pm 6.54$ & $78.3 \pm 5.39$ \\
\hline /AVCL/ & $57.8 \pm 3.18$ & $53.4 \pm 2.71$ & $49.8 \pm 0.24$ & $55.35 \pm 9.78$ & $50.8 \pm 4.04$ \\
\hline /PVCL/ & $69.6 \pm 2.79$ & $64.0 \pm 2.65$ & $75.5 \pm 0.25$ & $69.03 \pm 9.23$ & $59.6 \pm 6.94$ \\
\hline /MPL/ & $58.0 \pm 1.98$ & $54.3 \pm 1.89$ & $59.2 \pm 0.17$ & $57.47 \pm 2.48$ & $73.9 \pm 4.60$ \\
\hline /MNC-WI & $33.8 \pm 2.67$ & $34.1 \pm 2.21$ & $40.0 \pm 0.12$ & $33.37 \pm 2.67$ & $43.5 \pm 1.36$ \\
\hline IOC-W/ & $23.9 \pm 0.88$ & $22.9 \pm 0.93$ & $24.00 \pm 0.33$ & $22.56 \pm 1.18$ & $35 \pm 11.46$ \\
\hline /MH/ & $51.3 \pm 2.32$ & $42.4 \pm 2.25$ & $51.8 \pm 0.28$ & $47.13 \pm 5.99$ & $44.3 \pm 4.20$ \\
\hline$/ M H-M_{1 /}$ & $14.7 \pm 0.68$ & $11.8 \pm 0.73$ & $14.09 \pm 0.28$ & $13.04 \pm 1.94$ & $15.7 \pm 1.73$ \\
\hline$/ K c-C-A p /$ & $39.9 \pm 2.10$ & $33.7 \pm 1.71$ & $36.17 \pm 0.40$ & $37.15 \pm 3.37$ & $39.6 \pm 4.00$ \\
\hline /LCT/ & $53.3 \pm 1.62$ & $50.2 \pm 1.96$ & $63.6 \pm 0.18$ & $52.62 \pm 2.65$ & $42.7 \pm 2.75$ \\
\hline
\end{tabular}

J. Vet. Anat. 

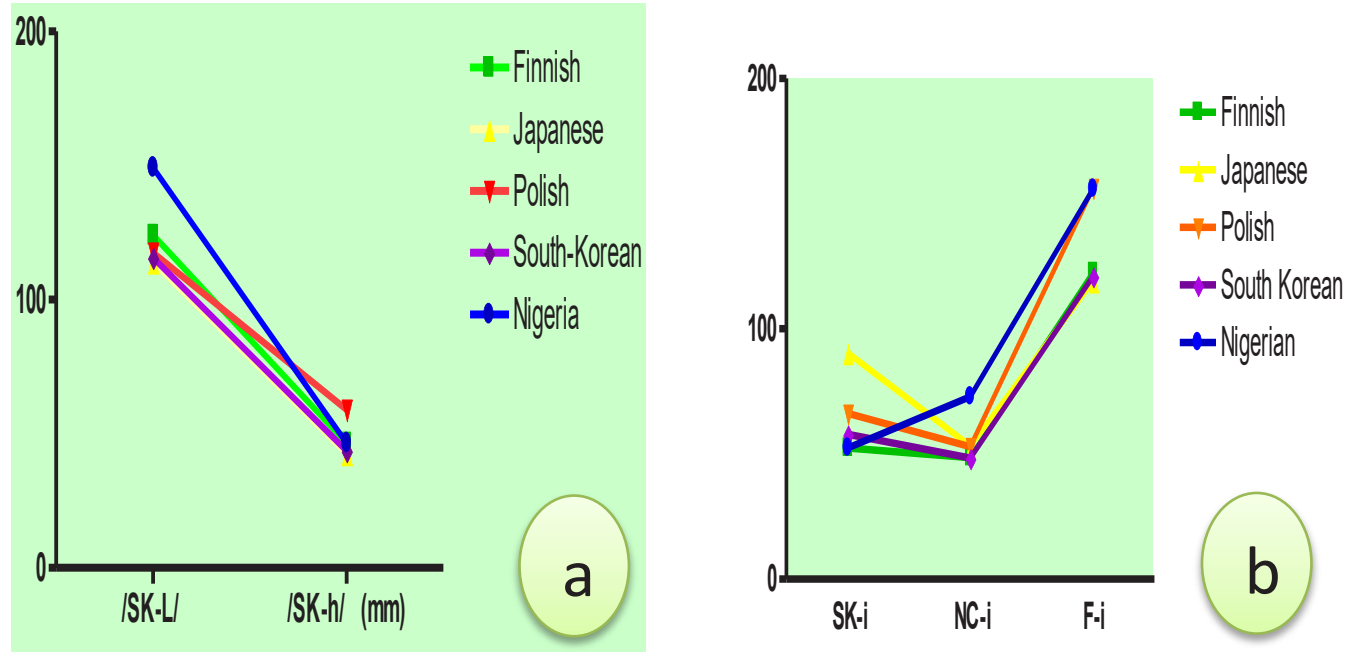

Fig (4a\&b): ANOVA representation showing skull length and height variations were significantly different $(P<0.0001)$ in tropical species (blue) but with (b) a sharpest rise in facial index relative to a low gradient neuro-cranial index and lowest skull index were each significantly different $(P<0.0001)$ in the species from Nigeria.

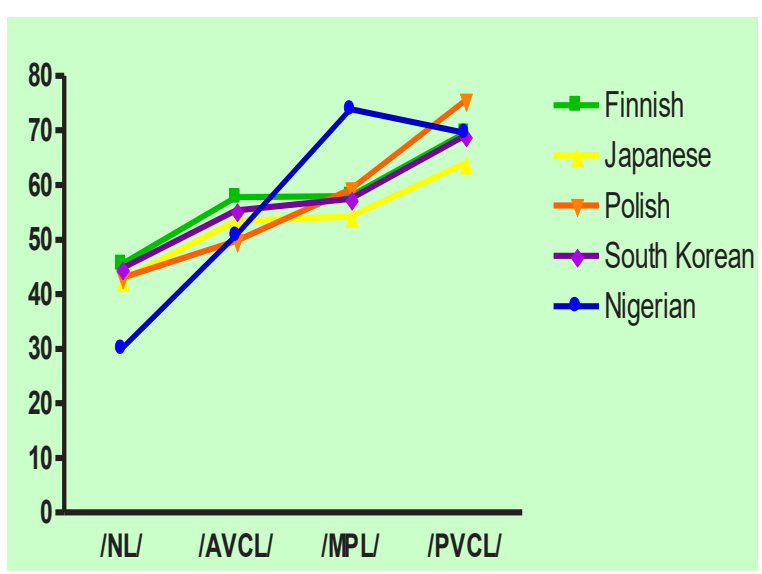

Fig (5): ANOVA representations showing a short nasal bone, a higher braincase (/PVCL/) relative to a rather compressed /AVCL/in tropical P.nyctereutes. The interaction is significant; posttest corrections result indicated high significance in all variables in the facial profile of tropical P. nyctereutes 

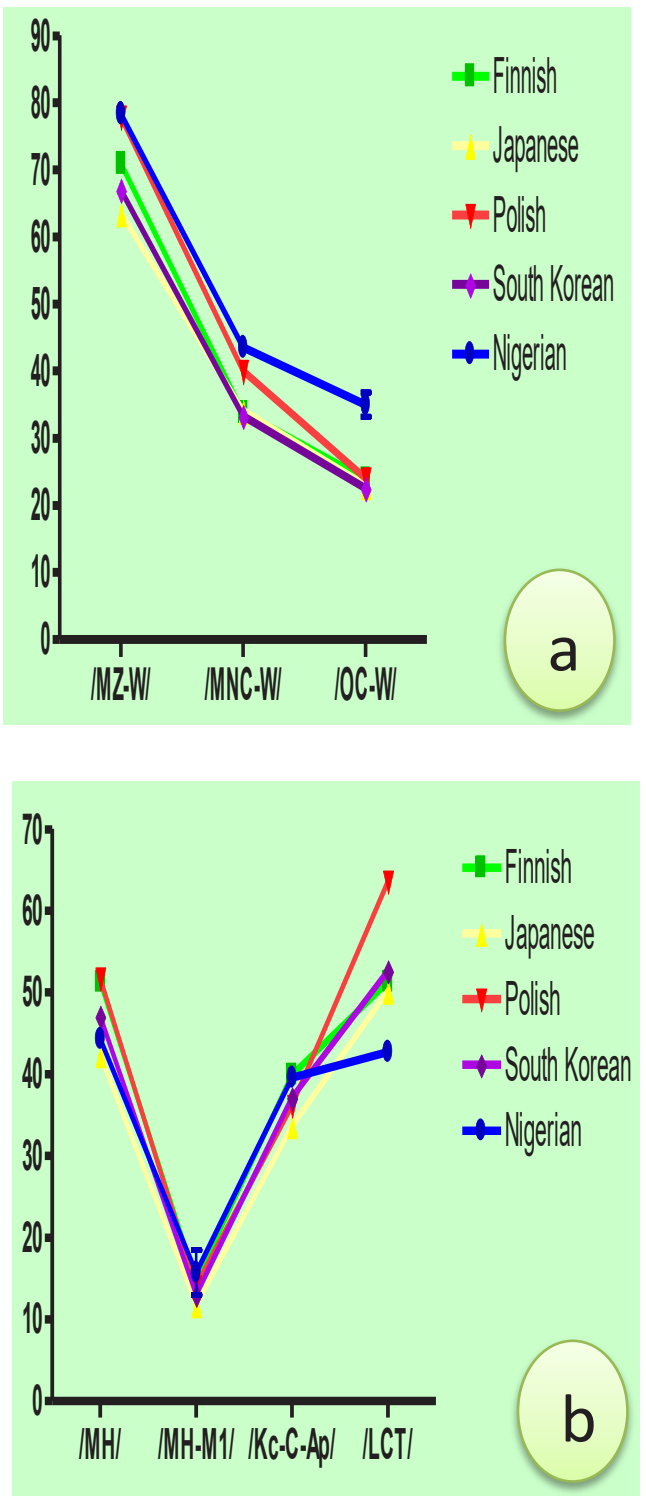

Fig (6a\&b): (a) ANOVA representation showing pattern of variation of /MZ-W/, /MNCW/, /OC-W/ and (b) /MH/, /MH-M1/, /Kc-C-Ap/ and /LCT/ with Bonferroni corrections 


\section{Animal species in this Issue}

\section{Raccoon Dog (Nyctereutes procyonoides)}

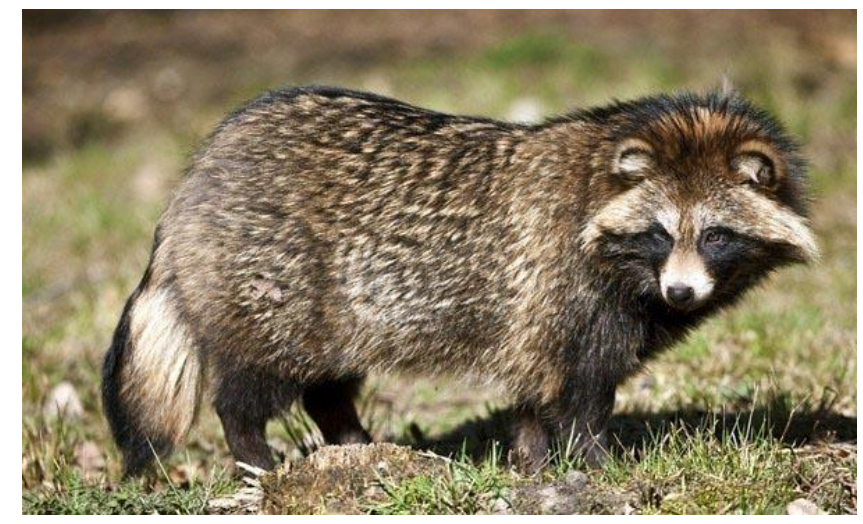

Kingdom: Animalia \& Phylum: Chordata \& Class: Mammalia \& Order: Carnivora \& Family: Canidae \& Genus: Nyctereutes \& Species: N. procyonoides

The raccoon dog is a canid indigenous to East Asia. It is the only extant species in the genus Nyctereutes. It is considered a basal canid species, resembling ancestral forms of the family.

Raccoon dog skulls greatly resemble those of South American foxes particularly crab-eating foxes, though genetic studies reveal they are not closely related. Their skulls are small, but sturdily built and moderately elongated, with narrow zygomatic arches. The projections of the skull are well developed, the sagittal crest being particularly prominent in old animals. In reflection of their omnivorous diets, raccoon dogs have small and weak canines and carnassials, flat molars and relatively long intestines (1.5-2 times longer than other canids). They have long torsos and short legs. Total lengths can range from 45 to $71 \mathrm{~cm}$ (18 to $28 \mathrm{in}$ ). The tail, at 12 to $18 \mathrm{~cm}$ (4.7 to $7.1 \mathrm{in}$ ) long, is short, amounting to less than $1 / 3$ of the animal's total length and hangs below the tarsal joints without touching the ground. The ears are short, and protrude only slightly from the fur.

The winter fur is long and thick with dense underfur and coarse guard hairs measuring $120 \mathrm{~mm}$ in length. The tail is darker than the torso. A dark stripe is present on the back which broadens on the shoulders, forming a cross shape. The abdomen is yellowish-brown, while the chest is dark brown or blackish.

Source: Wikipedia, the free encyclopaedia 